\title{
MEHL QUIZ SHOW: COMPREENDENDO A PÓS-GRADUAÇÃO COM O AUXÍLIO DA GAMIFICAÇÃO ${ }^{1}$
}

\author{
MEHL QUIZ SHOW: UNDERSTANDING POST-GRADUATION \\ WITH GAMING SUPPORT
}

\author{
Elizete de Fátima Veiga da Conceição ${ }^{2}$, Bruno Berton Ribeiro ${ }^{3}$, \\ Carlos Henrique da Costa Barreto ${ }^{4}$ e Taís Steffenello Ghisleni ${ }^{5}$
}

\section{RESUMO}

Este artigo apresenta o "MEHL Quis Show", um game do tipo quiz, composto de perguntas e respostas referentes a um curso de mestrado para ser aplicado e trabalhado com seus futuros alunos ingressantes. Desse modo, inserido na temática dos games e da gamificação, o trabalho tem como objetivos contextualizar os leitores sobre o mestrado; estudar o uso dos games como instrumento de interação social e ensino aprendizagem; e, ainda destacar a importância da gamificação no atual cenário de ensino na Era Digital, a partir de um olhar pelo modelo de Educação 3.0. A revisão bibliográfica somada à aplicação mostrou que os games por serem atividades voluntárias quando jogados requerem o engajamento dos jogadores, auxiliando no desenvolvimento do processo de ensino aprendizagem e na interação social dos sujeitos.

Palavras-chave: Ensino Superior, Ensino aprendizagem, Game, Interação Social.

\begin{abstract}
This article presents the "MEHL Quis Show", a quiz-type game, composed of questions and answers related to a master's course to be applied and worked with your future incoming students. Thus, inserted in the theme of games and gamification, the work aims to contextualize readers about the master's degree; study the use of games as an instrument of social interaction and teaching learning; and, still, to highlight the importance of gamification in the current teaching scenario in the Digital Era, from a look at the Education 3.0 model. The bibliographic review added to the application showed that games, being voluntary activities when played, require the engagement of players, helping in the development of the teaching-learning process and in the social interaction of the subjects.
\end{abstract}

Keywords: Higher education, Teaching and learning, Game, Social interaction.

1 Artigo resultante de iniciação científica.

2 Pedagoga (UFSM) Especialista em Gestão Educacional (UFSM) Mestre em Ensino de Humanidades e Linguagens (UFN) Doutoranda em Educação (UFSM).E-mail: Elizetefatimas@gmail.com

3 Produtor de Conteúdo Educacional. Graduado em Produção Audiovisual e Mestre em Ensino de Humanidades e Linguagens - Universidade Franciscana. E-mail.: brunocribeiro01@gmail.com

4 Pesquisador e Bolsista FAPERGS, Acadêmico de Publicidade e Propaganda pela Universidade Franciscana (UFN), Santa Maria - RS. E-mail: carloshcb123@gmail.com

5 Orientadora. Doutora em Comunicação. Professora do Curso de Publicidade e Propaganda e do Mestrado em Ensino de Humanidades e Linguagens da Universidade Franciscana - UFN. E-mail: taisghisleni@yahoo.com.br 


\section{INTRODUÇÃO}

Este trabalho aborda a temática sobre os games e a prática de gamificação ao lado de seus usos para o desenvolvimento do ensino aprendizagem e interações sociais entre os sujeitos. Quando um game for bem elaborado, pensado de acordo com o tipo de jogador, com seus objetivos bem definidos e com seus elementos de acordo com tais pretensões, ele pode proporcionar experiências que resultam em aprendizagens significativas e processos interativos entre os sujeitos (ALVES, 2015), da mesma maneira que com a Gamificação, seu uso pode se tornar efetivo e compreendido como uma dinâmica positiva e relativa ao cenário educacional (MCGONIGAL, 2010).

Por conseguinte, convencionou-se no MEHL, desde sua primeira oferta de curso, uma aula inaugural onde a coordenação do curso realiza uma apresentação dos processos, procedimento, etapas e disciplinas que fazem parte do programa, a fim de familiarizar os novos alunos com cada etapa do percurso do curso. Sendo assim, foi elaborado o MEHL Quiz Show, um jogo com perguntas e respostas, o qual foi pensado para auxiliar os alunos recém chegados ao Mestrado em Ensino de Humanidades e Linguagens (MEHL) da Universidade Franciscana. Tendo em vista que, quando estes fazem a seleção e iniciam o curso, ainda não estão familiarizado como todos os trâmites e requisitos exigidos para a conclusão do curso, esta dinâmica de Gamificação pode atuar como um instrumento integrador e dinamizador para todo o processo inicial. Assim, a elaboração seguida de uma aplicação experimental do MEHL Quiz Show rendeu a produção do presente artigo que, por sua vez, tem como objetivos 1) contextualizar os leitores sobre o MEHL; 2) estudar o uso dos games como instrumento de interação social e ensino aprendizagem; e, ainda 3) destacar a importância da gamificação no atual cenário de ensino na Era Digital, à partir de um olhar pelo modelo de Educação 3.0. O referido game foi produzido na disciplina de Seminário Integrado II, a partir de discussões realizadas em aula sobre o livro "Gamification”, de Flora Alves.

Optou-se por uma revisão bibliográfica a respeito da temática game, onde para compor o corpus deste trabalho utilizou-se de autores pesquisadores que estudam a utilização dos games para promover o desenvolvimento do ensino aprendizagem e a interação social. Também compõem este trabalho a arquitetura do game o roteiro e os itens utilizados.

\section{MESTRADO EM ENSINO DE HUMANIDADES E LINGUAGENS}

No decorrer deste tópico, apresentaremos o que é e quais são os objetivos do MEHL bem como uma revisão de literatura a respeito da temática "Games" como processos de interação social aliado ao ensino e aprendizagem juntamente de um olhar sobre seu uso efetivo dentro do ensino, a Gamificação, a partir de um olhar sobre desta dinâmica dentro do chamado modelo de Educação 3.0, da contemporânea Era Digital. Destas etapas, visa-se, por fim, fundamentar toda a atividade proposta e experimentada com os alunos integrantes do MEHL 
O Mestrado em Ensino de Humanidades e Linguagens - MEHL é um dos cinco cursos de pós-graduação Strito Sensu da Universidade Franciscana - UFN, que está sendo ofertado desde o segundo semestre de 2017. Segundo seu relatório geral de proposta de programa ( $\left.n^{\circ} 1198\right)$, a solicitação de oferta de novo curso foi encaminhado o Ministério da Educação via a Capes em 30 de julho de 2015, recebendo a aprovação em 15 de fevereiro de 2017 pela portaria no 259 do MEC (BRASIL. Ministério da Educação, 2017). Acrescentando, o MEHL tem como objetivo geral:

Qualificar professores em ensino de humanidades e linguagens para a pesquisa e prática docente, na educação básica e superior, por meio de investigações referentes aos conteúdos e aos processos de ensino e aprendizagem na educação básica e nos cursos de formação de professores, de modo a [re]significar e contribuir para a transformação do ensino em ambientes formais, não formais e informais. (UNIVERSIDADE FRANCISCANA, 2015, p. 15).

O MEHL conta com uma carga horária total de 442 horas em disciplinas, sendo 272 horas em disciplinas obrigatórias e 170 horas em disciplinas optativas, que devem ser cursada no período de 24 meses (quatro semestres). O MEHL conta em sua estrutura com duas linhas de pesquisa que podem ser localizadas na página do programa no site da Universidade Franciscana como ilustra a Tabela 1.

Tabela 1 - Linhas de pesquisa vinculadas ao MEHL.

\begin{tabular}{ll}
\hline \multirow{2}{*}{$\begin{array}{l}\text { Ensino, epistemologias e } \\
\text { formação docente }\end{array}$} & $\begin{array}{l}\text { Desenvolve investigações sobre epistemologias do ensino, políticas e gestão educacional sobre a forma- } \\
\text { ção inicial, continuada e em serviço de docentes e suas relações com as práticas docentes em espaços } \\
\text { formais, não formais e informais de ensino. As análises realizadas nesta linha de pesquisa evidenciam o } \\
\text { diálogo multidisciplinar entre as humanidades e linguagens nos processos de ensino e aprendizagem. } \\
\text { Contempla investigações relacionadas aos processos de ensino e aprendizagem de humanidades e } \\
\text { Ensino e práticas docentes }\end{array} \quad \begin{array}{l}\text { e linguagens. A ênfase das pesquisas está na criação, desenvolvimento, utilização de tecnologias } \\
\text { e informais em vista da transformação da prática docente. }\end{array}$ \\
\hline
\end{tabular}

Fonte: Disponível em: https://bit.ly/2Ogbbry. Acesso em: 17 jul. 2019.

A linha de pesquisa Ensino, epistemologias e formação docente, "propõe um conjunto de estudos que contempla a análise e a reflexão de bases epistemológicas [...], inter-relaciona os saberes docentes na criação de produtos e processos interativos para o desenvolvimento de uma prática inovadora e dinamizadora, qualificando docentes para contribuir na [re]significação e transformação no ensino de humanidades e de linguagens.” (UNIVERSIDADE FRANCISCANA, 2015, p. 13). Já a linha de pesquisa Ensino e prática docentes, enfatiza pesquisas "na criação, desenvolvimento, utilização de tecnologias e mídias, estratégias e metodologias dinamizadoras do ensino [...] em vista da transformação da prática docente" (UNIVERSIDADE FRANCISCANA, 2015, p. 13).

Agora que conhecemos um pouco sobre o MEHL, e de onde são retiradas as perguntas que fazem parte do jogo, vamos conhecer os conceitos teóricos de gamificação que foram adotados para a elaboração do MEHL Quiz Show. 


\section{GAMES - INTERAÇÃO SOCIAL E ENSINO APRENDIZAGEM}

Vários autores como Alves (2015), Hopf (2007) e, ainda, Libâneo (1994) tratam do tema do uso dos games em integração às práticas educacionais. Neste tópico, abordamos um apanhado de suas falas e considerações referentes à essa ferramenta adaptavelmente educacional - o que de seguimento fundamentará a prática de Gamificação, o nome dado à metodologia baseado no "uso prático" dos games que compreenderemos a seguir.

Alves (2015) nos destaca que todo um sistema em formate de game se trata de uma atividade voluntária, ou seja, uma atividade que não deve ser imposta aos participantes. Em sua obra, a autora pontua "o fato de ser livre, ser uma atividade voluntária contendo assim, um certo sentido de liberdade" (AVLES, 2015, p. 19). Uma vez participante, o indivíduo deve se encontrar motivado como na perspectiva de um desafio. Por conseguinte, na interpretação da autora, podemos compreender que o aluno deve sentir satisfação em realizar tal atividade e que somente assim o uso do game promoverá o resultado esperado, proposto pela sua sistemática.

Numa linha de pensamento, em concordância, os autores Hopf et al. (2007) chamam atenção quando falam que a atividade de jogar deve atuar ao jogador como uma alternativa de realização pessoal que possibilita a expressão de sentimentos, de emoção e propicia a aprendizagem de determinados comportamentos adequados e adaptativos à situação do game - o que se enquadra no processo esperado pela aplicação do MEHL Quiz Show quando necessário os alunos se adaptarem aos conhecimentos necessários referentes ao Mestrado para responderem as questões . Desse modo, o jogador precisa estar de acordo com o que é proposto pelo jogo, caso contrário a abordagem pedagógica sugerida não resultará em aprendizagem: se o aluno não tiver conhecimento das informações sobre o MEHL, não poderá participar das questões; por conseguinte, também não atingirá o estado de engajamento e nem terá despertado em si a competitividade para tal.

Libâneo, por sua vez, aborda fundamentalmente este fator resumindo tudo numa única questão: a motivação ao game. Segundo o autor, para que a aprendizagem aconteça a motivação é um fator expressamente determinante e pode se apresentar de duas formas, intrínseca ou extrínseca:

\footnotetext{
A motivação é intrínseca quando se trata de objetivos internos, como a satisfação de necessidades orgânicas ou sociais, a curiosidade, a aspiração pelo conhecimento; é extrínseca, quando a ação da criança é estimulada de fora, como as exigências da escola, a expectativa de benefícios sociais que o estudo pode trazer, a estimulação da família, do professor ou dos demais colegas. (LIBÂNEO, 1994, p. 88)
}

Sendo assim , com a motivação envolvendo um conjunto de fatores que precisam ser pensados antes da aplicação de um game, esses fatores dizem respeito ao aluno tanto como sujeito humano quanto social. Retomando Alves (2015) a autora enfatiza que a motivação pode ser consciente ou não, abordando os mesmos pontos da fala de Libâneo, em concordância. Por conseguinte, considerando todo o 
diálogo dos autores, quando se pensa um game, no que se refere ao desenvolvimento da aprendizagem, é necessário ponderar sobre o mesmo para que promova a produção de experiências. Existem duas maneiras de se pensar um game, seguindo essa ideia:

Ele pode ser pensado como o instrumento utilizado para se promover uma experiência, mas também pode ser pensado como resultado da combinação de uma série de elementos de forma a produzir determinada experiência. A segunda forma proporciona os "pensamentos de jogos", pois ela nos leva a buscar a melhor combinação de elementos e como correlacioná-los de modo a produzirmos a experiência adequada para que a aprendizagem ocorra (ALVES, 2015, p. 41).

O jogo permite ao aluno experimentar diferentes possibilidades. Permite ao mesmo ir além do tradicional e promove o desenvolvimento da aprendizagem à partir da interação social. Não obstante, o jogo, permitindo ao aluno criar, imaginar e fazer, "funciona como laboratório de aprendizagem, permite ao aluno experimentar, medir, utilizar, equivocar-se e fundamentalmente aprender" (VYGOTSKY e LEONTIEV,1998, p. 23). Então, no que se refere aos elementos de um game podemos destacar o relacionamento, que segundo Alves (2015, p. 44), "pessoas interagindo, amigos, colegas de time, oponentes, são elementos da dinâmica social que são também essenciais para o ambiente do game."

Ainda, no que diz respeito aos desafios que devem ser propostos pelo game, a autora coloca que "podem ser descritos como os objetivos que são propostos para os jogadores alcançarem durante o jogo. [...] São eles que mobilizam o jogador a buscar o estado de vitória” (ALVES, 2015, p. 45). Para tal, os jogadores precisam sentir-se desafiados a jogar, e isso só será possível se no momento de pensar o game seja definido, também, quais os objetivos a serem alcançados, ou seja (para o MEHL Quiz Show), o que queremos que este game proporcione em termos de ensino aprendizagem e interação social. Sendo assim, pode-se afirmar que, "o desafio é composto por uma meta, a incerteza quanto ao resultado, a percepção do jogador ou aprendiz quanto a ter a sua frente uma ferramenta ou um brinquedo e autoestima (ALVES, 2015, p. 62).

Ainda, se o game é pensado para ser jogado em grupos, os criadores do game precisam estar cientes que

[...] o que caracteriza o grupo não é a junção dos alunos, mas o desenvolvimento inter e intrapessoal e o estabelecimento de objetivos compartilhados, que se alteram conforme a estratégia proposta, o processo objetivado e seu processamento (ANASTASIOU, ALVES, 2004, p. 76)

Para tal, a importância de conhecer o grupo, ter objetivos claros e definidos, visando o que pretende alcançar. "Para pensarmos em uma solução de aprendizagem interativa e engajadora, temos que levar em consideração quem vai interagir e o que é importante para essa pessoa ou conjunto de pessoas" (ALVES, 2015, p. 76). Por isso, é necessário antes de pensar o game, pensar para qual público ele será utilizado, conhecer os jogadores. Contudo, para alcançarmos os objetivos propostos no game, o mesmo não pode ser muito difícil e nem muito fácil de ser jogado, difícil demais fazendo com 
que o jogador desista, e muito fácil fazendo com que o jogador não se sinta motivado e desafiado a alcançar a vitória. (ALVES, 2015).

\section{GAMIFICAÇÃO - UM OLHAR PELA EDUCAÇÃO 3.0}

Compreendida a pauta sobre que papel os games podem desempenhar positivamente ao cenário educacional quando pensados e elaborados dentro de métodos e atividades como é o MEHL Quiz Show, chegamos ao conceito de "Gamificação", que justamente trabalha e se refere a esse uso efetivo dos games em prol de um ensino, e também, pela visão de Barreto, Becker e Ghisleni (2018, p. 21) porque "é pertinente pensar e refletir mais sobre a questão do uso da Gamificação no processo educativo". Segundo os autores, esta dinâmica pode ser sintetizada como "a utilização de táticas ou elementos relativos à games para engajar pessoas - neste caso, os alunos - visando atingir objetivos ou resolver problemas através de formas dinâmicas e eficientes" (BARRETO; BECKER; GHISLENI, 2018, p. 11).

Pelo olhar da palestrante Jane McGonigal (2010), tal prática já vem manifestando-se positivamente em ambientes empresariais e institucionais - apresentando bons resultados - desde o início da década, o que na visão dela pode e deve ser apropriado, também, pela educação. Isso tudo porque, como devemos considerar, estamos no auge da chamada Era Digital, o cenário onde a tecnologia digital, a comunicação e a globalização invadem a vida e o cotidiano de praticamente todos os setores da nossa sociedade, como incluindo a educação (OLIVERIA, 2014). Sendo assim, a Gamificação no digital surge como um produto da nossa mais nova revolução educacional, da era contemporânea: o modelo de Educação 3.0.

Esta designação se refere ao formato de ensino cujas práticas podem (diferentemente do ensino nas décadas anteriores) totalmente serem integradas a tecnologias ou práticas digitais mais relativas ao "lúdico" - como tal é a gamificação - e onde também a troca de conhecimentos ocorre de maneira bilateral num diálogo de saberes entre alunos e professores. Na Educação 3.0, Lengel (2017) observa que os alunos precisam compreender como resolver problemas e trabalhar de forma colaborativa, comunicando e tirando o máximo possível do proveito da tecnologia que os rodeia. Gabriel (2018) confirma este pensamento e nos traz sua observação infalível e atemporal de que "tecnologia e humanidade andam de mãos dadas desde o início da nossa história", ou seja, de que este é o momento para se pensar na incorporação da prática ao escolar. Por conta disso,

O interesse pela inserção de ações de gamificação nas salas de aula vem crescendo, e isso têm gerado o interesse em saber mais a respeito da temática e como é possível melhorar os resultados de forma mais efetiva. Entre os vários benefícios encontrados no uso da gamificação, [...] a sugestão que fica para trabalhos futuros é que sejam exploradas as formas que estão sendo utilizadas atualmente para colaborar, na educação, para unir teoria e prática de forma que todos possam compreender como a teoria faz sentido na realidade (BARRETO; BECKER; GHISLENI, 2018, p. 20). 
Por conta disso, consideramos o MEHL Quiz Show, o game para o trabalho em questão: um jogo de perguntas e respostas elaborado - ainda que, de início, experimentalmente - para tomar a teoria dos aspectos relativos à dinâmica da Pós-Graduação e aplicá-la de maneira prática e ludificada aos ingressantes através da uma estrutura totalmente gamificada. Uma união de teoria e prática, mescla de informações curriculares e estruturais pertinentes ao curso, e ainda, trabalhando tudo de forma à instigar a participação dos alunos ao mesmo tempo em que incentiva suas interações sociais e lhes desenvolve um processo de ensino aprendizagem. Considerando então a fala de Oliveira (2014), Lengel (2017) e Barreto, Becker e Ghisleni (2018) trata-se este de um uso efetivo da Gamificação sob todo o contexto da Educação 3.0 inserida na nossa atual Era Digital.

\section{METODOLOGIA}

Como visto, desse modo o trabalho estruturou-se a partir de uma revisão bibliográfica a respeito da temática Game e Gamificação. Gil (2010) descreve que a revisão bibliográfica realizada para compor o corpus de um trabalho é fundamental, pois a mesma "[...] fornece fundamentação teórica ao trabalho, bem como a identificação do estágio do conhecimento referente ao tema" (GIL, 2010, p. 30). Ainda segundo o autor, a pesquisa bibliográfica apresenta como uma das principais vantagens, o fato de que permite uma maior cobertura sobre a temática, pois o pesquisador e o leitor terão acesso a uma quantidade mais elevada de informações.

\section{RESULTADOS E DISCUSSÕES}

Como o game foi aplicado em caráter experimental com os alunos do MEHL, alunos que já frequentam o curso e já sabem sua funcionalidade, podemos afirmar que a proposta foi bem aceita pelo grupo. Como estes alunos já estavam cientes das respostas, não foi possível alcançar todos objetivos inicialmente propostos pelo game. Assim, acreditamos que quando for aplicado com os alunos ingressantes no curso, será possível obter dados que contribuam para atingirmos totalmente o que foi proposto neste trabalho.

Contudo, foi possível observar que durante a realização de uma das perguntas, obtivemos um grande debate sobre ela, o que nos levou a repensar uma nova formulação. A pergunta em questão - pergunta inicial do game - foi construída da seguinte forma: "Posso defender minha dissertação sem ter concluído todas as disciplinas?”. Consultando a Coordenadora do MEHL, objetivamente isto "sim”, é possível. No entanto, acreditamos que a maioria dos participantes não tenha compreendido o significado da questão ou que não tivesse conhecimento desta possibilidade, pois a maioria não concordou e somente um aluno marcou que "Sim" inferindo o pensamento de "SIM, posso defender minha dissertação sem ter concluído todas as disciplinas". Por conta disso, optou-se por reformular 
a questão em uma maneira mais aberta: "O que é necessário e obrigatório para defender minha dissertação?”. Assim, o participante pode descrever todas as etapas das quais tem conhecimento serem necessárias para defender sua dissertação.

Assim, a partir deste feedback dos mestrandos, será possível repensar o jogo antes de sua aplicação com os alunos ingressantes do MEHL. De seguimento, apresentamos a arquitetura do jogo para uma compreensão sistemática e estrutural aos leitores das regras, roteiro e itens utilizados.

\section{MEHL QUIZ SHOW - ARQUITETURA DO GAME}

\section{INFORMAÇÕES GERAIS}

Figura 1 - Logo "MEHL Quiz Show".

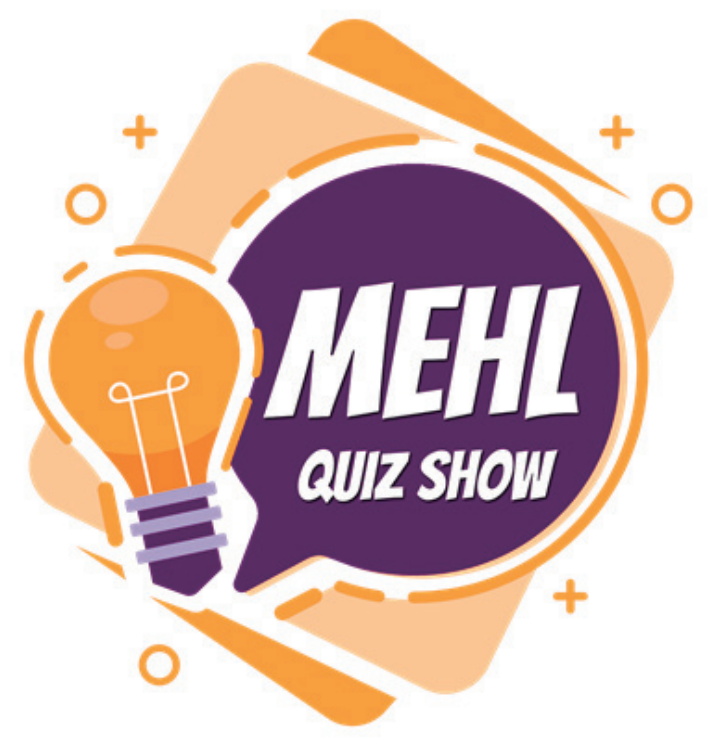

Fonte: Elaboração própria

- O quiz é constituído por 25 perguntas;

- É expressamente proibida a utilização de qualquer meio tecnológico como auxiliar nas respostas, passível de desclassificação.

\section{OBJETIVOS DO GAME}

O jogo, com perguntas relacionadas a estrutura de funcionamento do Mestrado em Ensino de Humanidades e Linguagens, tem os seguintes objetivos:

- Fornecer mais informações sobre a pós-graduação e o Mestrando de Ensino de Humanidades e Linguagens para os alunos;

- Apresentar as principais etapas do processo de Mestrado; 
- Investigar os conhecimentos preexistentes sobre o Mestrando de Ensino de Humanidades e Linguagens por parte dos alunos recém chegados ao curso; e

- Propiciar a socialização entre os novos alunos do Mestrado de Ensino de Humanidades e Linguagens.

Figura 2 - Slides de apresentação das perguntas e respostas do jogo "MEHL Quiz Show".

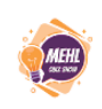

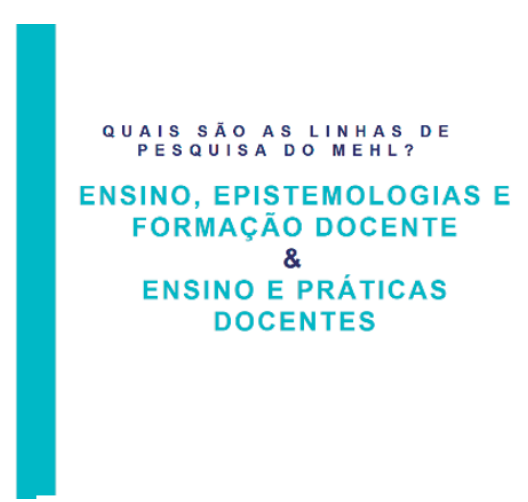

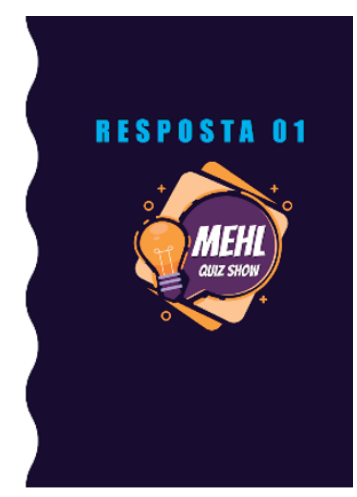

Fonte: Construção própria.

TEMPO DE PARTIDA

- $\quad$ jogo foi criado para ter a duração entre 30 minutos à 1 hora para sua aplicação

\section{FASES DO GAME}

- $\quad$ Fase 01 - Perguntas Gerais;

- $\quad$ Fase 02 - Disciplinas do MEHL;

- Fase 03 - Pré-projeto \& Qualificação;

- Fase 04 - Plataforma Brasil, Comitê de ética e Proficiência;

- Fase 05 - Elaboração Da dissertação e defesa final.

Figura 3 - Slides de apresentação das fases do jogo"MEHL Quiz Show"
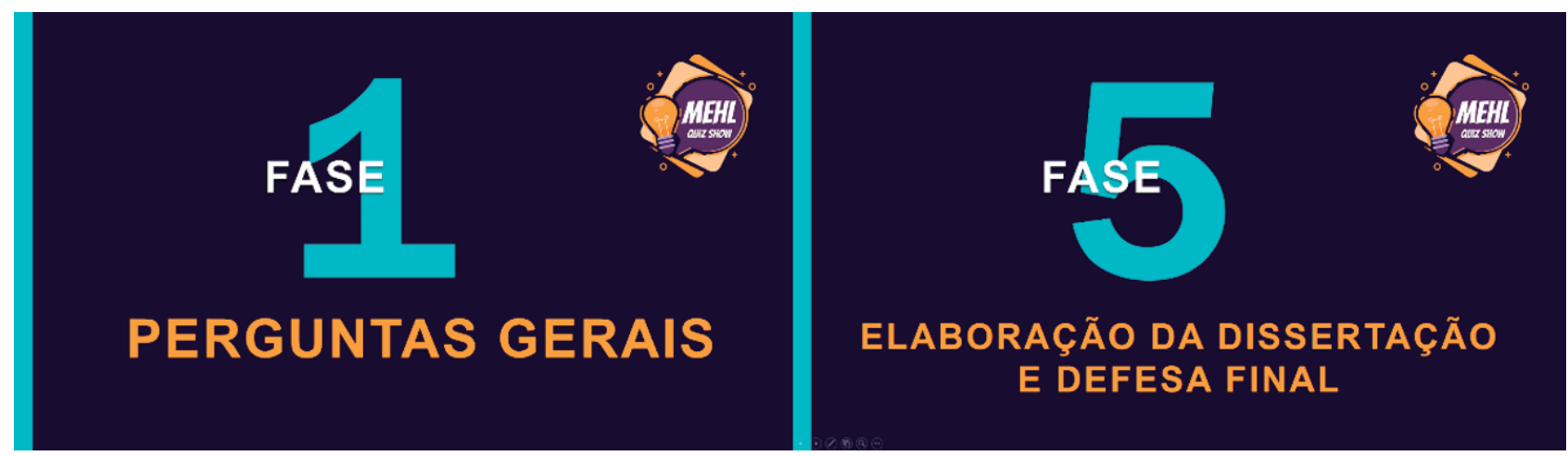

Fonte: Construção própria 


\section{REGRAS PARA JOGAR}

- Dividir os participantes em dois grupos.

- Para começar um integrante de cada grupo, previamente escolhido joga o dado, o grupo que tirar o maior número começa respondendo às perguntas.

- Para cada rodada o grupo precisa escolher um representante para responder à pergunta.

- A partir do momento da pergunta, esse representante poderá se reunir com o seu grupo no qual poderá ajudá-lo na resposta da pergunta.

- Após cada pergunta o grupo terá 30 segundos para responder ou passar à pergunta para o outro grupo, contudo se o outro grupo não quiser responder à pergunta, ele poderá devolver a pergunta para o primeiro grupo, que terá que responder corretamente, ou pagar uma prenda (enfrentar um desafio), que estarão descritos em cartas aleatórias, que serão sorteadas pelo grupo que errou a pergunta.

- Cada resposta correta vale 10 pontos. Se o grupo responder errado perderá 5 pontos, a ser que o participante pague a prenda.

- Ganha quem fizer mais pontos até o final das perguntas. Em caso de empate, a equipe que respondeu a última resposta correta será a vencedora.

Tabela 2 - Perguntas utilizadas durante o game.

\begin{tabular}{l}
\hline Quais são as linhas de pesquisa do MEHL? \\
Quem é o coordenador(a) do MEHL? \\
Onde você poderá ir para tirar dúvidas sobre o MEHL? \\
Qual é o público alvo do MEHL? \\
Quantas horas de carga horária de disciplinas obrigatórias é preciso? \\
Quantas horas de carga horária de disciplinas optativas é preciso? \\
Para qual disciplina eu apresento meu projeto de pré-qualificação? \\
Preciso ser proficiente em alguma língua estrangeira para defender minha dissertação? \\
Quando é necessário enviar minha pesquisa para o comitê de ética? \\
Quantos professores farão parte da banca de defesa da dissertação? \\
O que é necessário e obrigatório para defender minha dissertação? \\
A disciplina de Teoria de Ensino e Aprendizagem é obrigatória ou optativa?
\end{tabular}

Fonte: elaboração própria

Todas as perguntas foram elaboradas conforme informações pesquisadas na página de internet do MEHL e também do material utilizado na aula inaugural do MEHL de 2019. 
Figura 4 - Convite para aula inaugural do MEHL

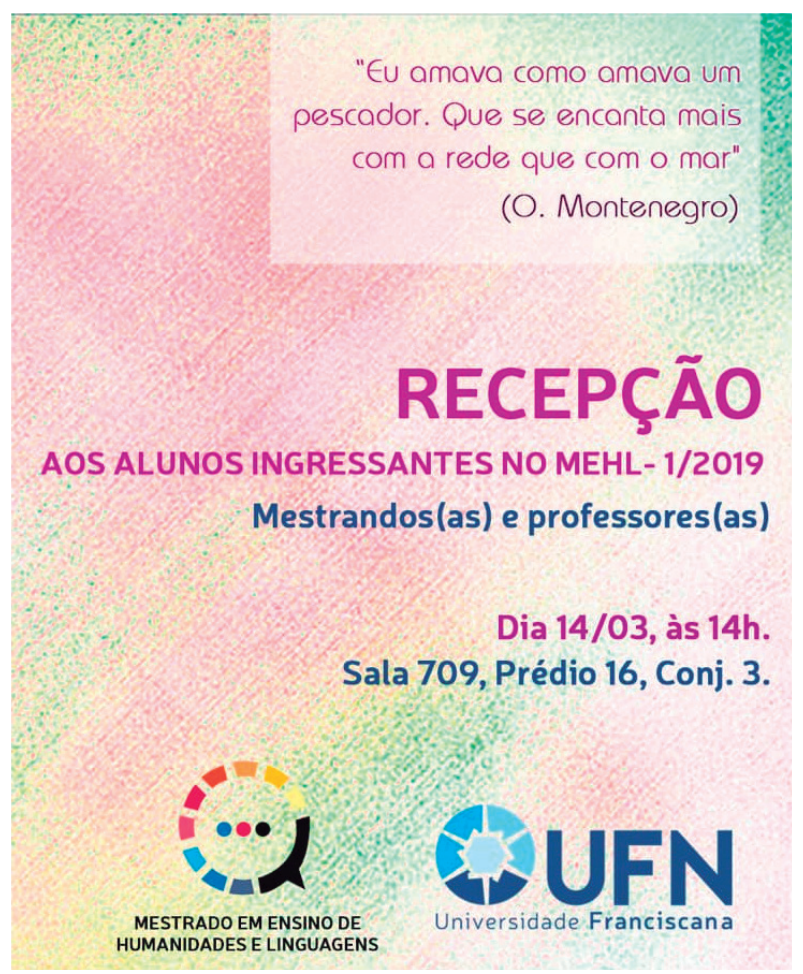

Fonte: https://bit.ly/3ciRreO.

\section{PRENDAS DO GAME}

Tabela 3 - Prendas realizada no "MEHL Quiz Show"

\section{PRENDAS REALIZADAS NO MEHL QUIZ SHOW}

Colocar uma pessoa do grupo como se fosse uma estátua, sendo permitido a todos os participantes alterar a posição da estátua a seu modo.

Marcar compasso com a mão esquerda e com a direita, escrever ao mesmo tempo com as duas mãos uma frase.

Dizer de trás para diante os meses do ano.

Dizer de trás para diante o alfabeto.

Com a ponta do pé esquerdo, fazer círculos no chão e ao mesmo tempo assinar o nome com a mão direita.

Sentar-se no chão e levantar-se sem apoiar-se com as mãos

Imitar três bichos (macaco, boi, cachorro) sem rir.

Cante uma música de boca fechada.

Dizer muito rápido: o rato roeu a rolha da garrafa de rum do rei da Rússia;

Dizer quatro palavras em inglês;

Faça um colega dar risada sem tocar no corpo dele.

Fonte: Construção própria

\section{RESULTADO E PREMIAÇÃO}

A equipe vencedora será a que tiver acumulado o maior número de pontos. A equipe com maior pontuação ganhará um prêmio simbólico (que será escolhido pela comissão organizadora do quiz), e terá sua foto divulgada nas redes sociais do MEHL. 


\section{CONSIDERAÇÕES FINAIS}

Após a aplicação e exposição experimental aos alunos do MEHL, concluímos que o jogo teve uma boa aceitação por parte do grupo, conforme os alunos ficaram instigados a participar, tendo se estabelecido um amplo e participativo debate participativo sobre as questões aplicadas. Porém, como estes alunos já estavam frequentando o curso a um determinado tempo (uma fase de experimentação para o game, apenas) e já estavam cientes de quais os passos necessários para concluir o mestrado, não foram todos os objetivos propostos atingidos integralmente. Assim, considerando o exposto o nosso texto de que um game é o sistema engajador definido por regras onde são trabalhadas as interatividades entre os jogadores - ainda com a possibilidade de feedback de toda a atividade - é pela análise desta aplicação experimental do MEHL Quiz Show que percebemos o game cumprir sua meta: ao mesmo tempo em que desafia os alunos, garante sua interações positivas construídas pelas atividades que ele propõe.

Sendo assim, após os ajustes que vimos necessários, já é viável a ideia de aplicá-lo aos alunos recém-chegados no MEHL. Uma vez que estes serão os novos ingressantes, e que ainda não estão informados sobre todos os aspectos e detalhes relativos ao MEHL e sua dinâmica, isso irá garantir maior competitividade entre os grupos tornando o jogo mais atrativo e com uma possibilidade efetiva de alunos "vencedores". Conclui-se que o MEHL Quiz Show representa um game que, quando bem organizado e pensando para os jogadores, garantirá neles não apenas a motivação para jogar e para cumprir seus objetivos, mas uma produção de experiências dentro do Mestrado. O game assim representa uma forma de desenvolver o ensino e a aprendizagem auxiliando nos processos de interação social entre os sujeitos envolvidos - os jogadores - tal e qual segue os caminhos para uma educação inovadora dentro de um contexto também inovador como o compreendido Modelo 3.0.

O MEHL Quiz Show foi elaborado com o cuidado de não se tratar apenas de mais um game com atividades quaisquer, sem objetivos específicos e sem propósito além do entretenimento, uma vez que isto não despertará engajamento nem interesse algum entre os membros participantes e nem se tornará uma prática de Gamificação para a Educação 3.0. Além dos objetivos bem elaborados e direcionados a Mestrado em Ensino de Humanidades e Linguagens, o game se mostrou atrativo, provocou esse engajamento, levantou questionamentos e, principalmente, instigou a competitividade.

A aplicação do MEHL Quiz Show também nos possibilita a visão de que a Gamificação é uma prática, uma ferramenta educacional que deve ser especialmente pensada para captar o interesse e a participação dos membros de num determinado grupo. A aplicação do MEHL Quiz Show promove a aprendizagem, instiga a competitividade e torna-se para estes membros, os seus alunos participantes, um exemplo efetivo de Gamificação como ferramenta educacional da Educação 3.0, da Era Digital e do Mestrado em Ensino de Humanidades e Linguagens que se resolve tanto nos objetivos do game, como para os objetivos propostos deste trabalho. 


\section{REFERÊNCIAS}

ALVES, F. Gamification: Como criar experiências de aprendizagem engajadoras: um guia completo: do conceito a prática, 2. ed. São Paulo: DVS Editora, 2015.

ANASTASIOU, L. das G. C.; ALVES, L. P. Processos de ensinagem na universidade: pressupostos para as estratégias de trabalho em aula. 3. ed. Joinville, SC: Univille, 2004.

BRASIL. Ministério da Educação. Reconhecimento de curso de Pós-graduação no 259. Brasília,

DF: Ministério da Educação, 15 fev. 2017. Assunto: Portaria de Aprovação do Programa de Pós-Graduação MEHL.

GABRIEL, M. Educar. São Paulo: Saraiva, 2013.

BARRETO, C. H. da C.; BECKER, E. L. S.; GHISLENI, T. S. Gamificação: uma prática da educação 3.0. Research, Society and Development, v. 8, n. 4, p. 2, 2019.

GIL, A. C. Como elaborar projetos de pesquisa. 5. ed. São Paulo: Atlas, 2010.

HOPF, T.; FALKEMBACH, A. M. G.; ARAÚJO, V. F. O uso da tecnologia x3d para desenvolvimento de jogos digitais. Novas tecnologias na educação. v.5, n.2. Porto Alegre, 2007. Disponível em: https://bit.ly/3kYuamx. Acesso em: 10 Jun. 2019.

KAPP, K. M. The Gamification of Learning and Instruction: game-based methods and strategies for training and education. São Francisco: Pfeiffer, 2012.

LIBÂNEO, J. C. A avaliação escolar. São Paulo: Cortez, 1994.

MCGONIAL, J. Gaming can make a better world. TED. 2010. Disponível em https://bit.ly/3btIYGn. Acesso em 02 de janeiro de 2021.

MORIN, E. A cabeça bem-feita: repensar a reforma, reformar o pensamento. 8. ed. Rio de Janeiro: Bertrand Brasil. 8. ed. Rio de Janeiro: Bertrand Brasil, 2003. 
RIBEIRO, B. C.; BÜRGER, C. A. C.; GHISLENI, T. S. Reflexos do ensino aprendizagem no mestrado de ensino de humanidades e linguagens da universidade franciscana: a relação teoria e prática. VIII Congresso Internacional de Educação, 2019. Disponível em: https://bit.ly/3rtamtM. Acesso em: 17 jul. 2019.

UNIVERSIDADE FRANCISCANA. Dados da Proposta de Programa/Curso Novo. ${ }^{\circ}$ 1198, Santa Maria, RS: Universidade Franciscana, 30 jul. 2015. Assunto: Relatório Geral enviado ao CAPES para autorização do Programa de Mestrado em Ensino de Humanidades e Linguagens - MEHL.

VYGOTSKY, L.S. e LEONTIEV, A. Linguagem, desenvolvimento e aprendizagem. São Paulo: Edusp, 1998. 